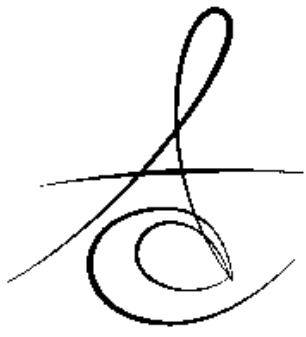

\title{
FARKLI DEZENFEKSİYON YÖNTEMLERİNİN CAD / CAM VE KONVANSİYONEL AKRİLİK REZİNLERİN YÜZEY SERTLİĞİNE ETKİSİ
}

\section{EFFECT OF VARIOUS DISINFECTION METHODS ON THE SURFACE HARDNESS OF CAD/CAM AND CONVENTIONAL ACRYLIC RESINS}

\author{
Dr. Süleyman ÇAĞATAY DAYAN*
}

Makale Kodu/Article code: 3923

Makale Gönderilme tarihi; 07.12.2018

Kabul Tarihi: 03.04 .2019

\section{öz}

Amaç: Bu çalışmanın amacl, farklı dezenfeksiyon yöntemlerinin (\%2 glutaraldehit, \%5 sodyum hipoklorit ve mikrodalga) yeni üretilen prefabrike olarak polimerize edilmiş CAD/CAM akrilik rezin, ISı ile ve kimyasal polimerize olan akrilik rezinlerin yüzey sertliği üzerindeki etkisini değerlendirmektir.

Gereç ve yöntem: $15 \mathrm{~mm}$ çapında $2 \mathrm{~mm}$ kalınlığında disk şeklinde hazırlanan örnekler kontrol ve 3 farklı test grubuna ayrılmıştır $(n=8)$ : Grup 1: kontrol, $37^{\circ} \mathrm{C}$ de distile su içinde; Grup 2: \%2'lik glutaraldehit; Grup 3: \%5'lik sodyum hipoklorit; Grup 4: mikrodalga dezenfeksiyonu ( $650 \mathrm{~W} / 6$ dak). G2 ve G3 örnekleri bir saat boyunca dezenfektan solüsyonda bekletilmiştir. Yüzey sertliği ölçümleri (Vickers Sertliği), 2 yönlü ANOVA ve Tukey's Honestly Significant Difference testi $(a=.05)$ kullanılarak analiz edilmiştir.

Bulgular: Tüm gruplarda en yüksek yüzey sertlik değerleri kontrol gruplarında bulunmuştur. Prefabrike olarak polimerize edilmiş CAD/CAM akrilik rezinler bütün gruplarda en yüksek yüzey sertliği göstermiştir $(p<0,001)$. \%5'lik sodyum hipoklorit dezenfeksiyonu, ISI ile ve kimyasal polimerize olan akrilik rezinlerin yüzey sertliği üzerinde etkili olmuştur ( $p<0,001)$.

Sonuçlar: $\mathrm{Bu}$ çalışmanın sınırları dahilinde, yeni üretilen prefabrike olarak polimerize edilmiş CAD/CAM akrilik rezinlerin yüzey sertliği, dezenfektan yöntemlerinden bağımsız olarak dezenfeksiyondan etkilenmemiştir.

Anahtar Kelimeler: Akrilik rezin, Dezenfektan solüsyon, Dezenfeksiyon, CAD/CAM akrilik, Protez Kaide Materyali

\section{ABSTRACT}

Aim: The aim of the current study was to assess the effect of simulated disinfections ( $2 \%$ glutaraldehyde, $5 \%$ sodium hypochlorite, and microwave) on the surface hardness of newly introduced pre-polymerized acrylic resin, heat and self cured acrylic resin.

Materials and Methods: Disc shaped specimens, 15 $\mathrm{mm}$ diameter and $2 \mathrm{~mm}$ thickness, were divided into a control and 3 test groups $(n=8)$ : Group 1: control, stored in distilled water at $37^{\circ} \mathrm{C}$; Group 2: $2 \%$ glutaraldehyde; Group 3: 5\% sodium hypochlorite; Group 4: microwave disinfection ( $650 \mathrm{~W} / 6 \mathrm{~min}$ ). G1 to G3 were immersed for an hour in the disinfectant solution. Measurements of surface hardness (Vickers Hardness) were analyzed using 2-way ANOVA and Tukey's Honestly Significant Difference (HSD) test $(a=.05)$.

Results: The control groups showed the highest surface hardness values in all groups. Pre-polymerized block acrylic resin showed the highest surface hardness in all of the groups $(p<0,001)$. The $5 \%$ sodium hypochlorite disinfection had an effect on the surface hardness of heat and self cured acrylic resins $(p<0,001)$.

Conclusions: Within the limitation of the current study, surface hardness of newly introduced prepolymerized acrylic resin was not affected by disinfection regardless of the disinfectant methods.

Keywords: Acrylic resin, Disinfectant solution, Disinfection, CAD/CAM acrylic, Denture Base Material

\footnotetext{
${ }^{*}$ Program of Dental Technicians, Istanbul University-Cerrahpasa, Istanbul.
} 


\section{Gíriş}

Diş hekimliğinde klinik ve laboratuvar uygulamalar sırasında el aletleri ve laboratuvar gereçleri patolojik organizmalar ile kontamine olabilmektedir. Kan ve tükürük sadece hepatit $B$ ve HIV virüslerinin potansiyel kaynağını oluşturmamakta aynı zamanda grip, herpes, pnömoni ve tüberküloz gibi hastalıklara neden olan diğer tehlikeli virüs ve bakterileri de taşıyabilmektedir. ${ }^{1,2}$

Tam ve hareketli protezlerin dezenfeksiyonunda otoklav ile sterilizasyon kullanılamadığı için kimyasal solüsyonlar veya mekanik aletler ile dezenfekte edilmeleri gerekmektedir. ${ }^{3}$ Etkili bir dezenfeksiyon sağlamak için glutaraldehit, sodyum hipoklorit, iyodoform, karbondioksit, klorheksidin veya alkolik çözeltileri içeren çeşitli kimyasal dezenfektanların kullanımı önerilmektedir. ${ }^{4-6}$ Alkalin peroksit solüsyonları, hipoklorit ve sirke solüsyonları gibi birkaç protez temizleyicisinin de etkili kimyasal dezenfektan olduğu kanıtlanmıştır., Bununla beraber, kimyasal dezenfeksiyonun protez kaide materyallerinin yüzey özelliklerini olumsuz etkilediği düşünen bazı araştırmacılar mikroorganizmaları yok etmek için kanıtlanmış bir yöntem olan mikrodalga enerjisini alternatif olarak önermektedir. ${ }^{9,10}$

Çağdaş protetik diş hekimliğinin amaçları arasında, 80 yıldan daha uzun bir zamandır geleneksel yöntemlerle üretilen hareketli protezlerin üretim süreci ile ilişkili dezavantajları azaltmak ve polimetil metakrilat (PMMA) malzemesinin özelliklerini geliştirmek yer almaktadır. Hareketli protezlerin üretiminde, bilgisayar destekli tasarım ile bilgisayar destekli üretim (CAD/ CAM) sistemlerinin kullanılmaya başlanması ile geleneksel yöntemlerde karşılaşılan problemlerin azalması ve hareketli protez üretim sürecinin kolaylaşması beklenmektedir. ${ }^{11}$ CAD/CAM'de kullanılan PMMA esaslı materyallerin kimyasal yapıları, mekanik özellikleri ve polimerizasyon yöntemleri geleneksel PMMA'lara göre farklıdır. Yüksek sıcaklık ve basınç altında standart koşullarda endüstriyel olarak elde edilen bu polimerler düşük artık monomer ve yüksek derecede çapraz bağlantı içerdikleri için geleneksel alternatiflerine göre daha üstün biyolojik ve mekanik özellikler sunabilir. ${ }^{12-14}$

Rijit polimerlerin yüzey sertliğini değerlendirmede kullanılan Vickers sertlik yöntemi, belirli bir yük altında yüzey sertliği test edilecek materyalin yüzeyine kare tabanlı piramit şeklindeki bir ucun batırılması ve yük ortadan kalktıktan sonra meydana gelen izin köşegenlerinin ölçülmesi esasına dayanmaktadır. ${ }^{15}$

Laboratuvarda bitirilmiş protezlerin klinikte hastaya teslim edilmesinden önce enfeksiyon kontrolü için dezenfekte edilmeleri gerekmektedir. Ancak mevcut dezenfeksiyon yöntemlerinin protez kaide materyallerine olan etkisi tam olarak bilinmemektedir. Bu çalışmanın amacı, dezenfektan solüsyonların ve mikrodalga ile dezenfeksiyonun prefabrike olarak polimerize edilmiş CAD/CAM akrilik blokların ve ısı ile ve kimyasal polimerize olan protez kaide materyallerinin yüzey sertliğine olan etkisini değerlendirmektir. Çalışmanın sıfır hipotezi, farklı dezenfeksiyon yöntemlerinin, farklı yöntemlerle elde edilmiş olan protez kaide materyallerinin yüzey sertliği üzerinde istatistiksel olarak anlamlı bir etkisinin olmadığıdır.

\section{GEREÇ VE YÖNTEM}

$\mathrm{Bu}$ çalışmada üç farklı protez kaide materyali kullanılmıştır: ısı ile polimerize olan akrilik rezin, kimyasal polimerize olan akrilik rezin ve prefabrike olarak polimerize edilmiş CAD/CAM akrilik blok (Şekil 1) (Tablo 1). Her üç protez kaide materyalinden 32 adet örnek hazırlanmıştır. CAD/CAM akrilik rezin örnekler için $15 \mathrm{~mm}$ çapında üç boyutlu tasarımlar gerçekleştirilerek STL dosyası olarak kaydedilmiştir ve 5-eksenli milling ünitesinde hazır bloktan üretilmiştir (Ceramill Motion 2; Amann Girrbach, Koblach, Avusturya). Daha sonra bu örnekler elmas bıçak kullanılarak (IsoMet Blade 15 LC; Buehler, Illinois, ABD) örnek kesme cihazıyla (IsoMet 1000; Buehler, Illinois, ABD) 2 mm kalınlığında kesilmiştir. $15 \mathrm{~mm}$ çapında $2 \mathrm{~mm}$ kalınlığında üretilen CAD/CAM akrilik diskler, ISı ile ve kimyasal polimerize olan akrilik rezin örneklerin hazırlanmasında kalıp olarak kullanılmıştır. CAD/CAM akrilik disklerin üzeri yüksek vizkoziteli polivinilsiloksan ölçü malzemesiyle (Silagum Putty; DMG, Hamburg, Almanya) kaplandıktan sonra tip 3 sert alçı ile geleneksel olarak muflalanmıştır. Alçı sertleştikten sonra CAD/ CAM akrilik diskler çıkartılmış ve oluşan kalıp boşluğuna üretici firmanın talimatları doğrultusunda karıştırılan ISı ile polimerize olan akrilik tepilmiştir. Örneklerin polimerizasyonu 9 saatte $74^{\circ} \mathrm{C}$ sıcaklıkta otomatik polimerizasyon ünitesinde gerçekleştirilmiştir (Kavo EWL 5501; Kavo Electrotechnisches Werk $\mathrm{GmbH}$, Berlin, Almanya). Kimyasal polimerize olan akrilik örneklerin hazırlanması için ısı ile polimerize edilen akrilik örneklerin hazırlanmasında kullanılan benzer 
Tablo 1. Çalışmada kullanılan materyaller

\begin{tabular}{|c|c|c|}
\hline Akrilik rezin & Ürün ismi & Üretici firma \\
\hline $\begin{array}{l}\text { Kimyasal polimerize olan } \\
\text { akrilik } \\
\text { Isı ile polimerize olan } \\
\text { akrilik } \\
\text { Prefabrike olarak } \\
\text { polimerize edilmiş } \\
\text { CAD/CAM akrilik }\end{array}$ & $\begin{array}{c}\text { Weropress } \\
\\
\text { Paladent } \\
20 \\
\text { M-PM Disc }\end{array}$ & $\begin{array}{c}\text { Merz Dental GmbH, } \\
\text { Lütjenburg, Almanya } \\
\text { Kulzer-Mitsui_Chemicals } \\
\text { Group, Hanau, Almanya } \\
\text { Merz Dental GmbH, } \\
\text { Lütjenburg, Almanya }\end{array}$ \\
\hline
\end{tabular}

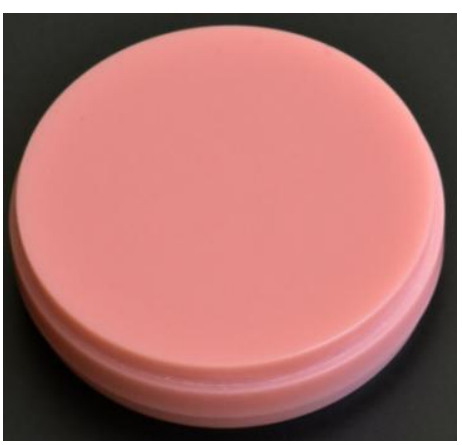

Şekil 1. Prefabrike olarak polimerize edilmiş CAD/CAM akrilik.

yöntemle kalıp boşluğu oluşturulmuştur ve üretici firmanın talimatları doğrultusunda mufla içerisindeki alçının sıcakığının polimerizasyonu desteklemesi için mufla termostatlı pişirme firınında $35-40{ }^{\circ} \mathrm{C}^{\prime} \mathrm{ya}$ kadar ısıııımışıı. Daha sonra, üretici firmanın talimatları doğrultusunda toz ve likit oranı $30 \mathrm{~g} / 5 \mathrm{ml}$ olacak şekilde karıştırılan akrilik muflaya tepilmiş ve 15 dakika hidrolik pres altında basınca maruz bırakıımışır. Polimerizasyonu tamamlanan örneklerin kenar fazlalıkları düşük devirde tungsten karbid frezle düzeltilmiştir. Ölçümlerin yapılabilmesi için her üç rezin grubunun örnek yüzeyleri tesviye işlemi sonrasında 600 gritlik silikon karbid kağıt zımparalarla (Met Rolls; Kemet, Londra, İngiltere) su altında düzleştirilmiştir. Daha sonra iki aşamalı olarak cilalanmışlardır; önce $90 \mathrm{sn}$ süre ile dental pomza (IMIPOMZA; Imıcryl, Konya, Türkiye) ve su karışımıyla daha sonra ise universal polisaj pastası (Universal Polishing Paste; Ivoclar Vivadent, Schaan, Lihtenştayn ) ile parlatılıp test için uygun yüzeyler hazırlanmıştır. Cilalamanın ardından bütün örnekler 24 saat $37 \mathrm{C}^{\prime \prime}$ ta distile su içinde bekletilmiştir. Daha sonra her gruba ait 32 adet örnek $4(n=8)$ eşit gruba ayrılmıştır. 1. Grup 1 saat daha aynı distile su içinde bekletilmiş ve işlem yapılmamış kontrol grubunu, 2. Grup 1 saat boyunca \% 2'lik glutaraldehit (Klorhex; Drogsan ilaç, Ankara, Türkiye) solüsyonunda bekletilen grubu, 3. Grup 1 saat boyunca \%5'lik Sodyum Hipoklorit (Wizard; Rehber Kimya, İstanbul, Türkiye) solüsyonunda bekletilen grubu (Şekil 2) ve 4. Grup $150 \mathrm{~mL}$ su içinde bulunan örneklerin 650W güç ve 3 dakika süre ile mikrodalga (MD 2084; Arçelik, İstanbul, Türkiye) dezenfeksiyonuna ${ }^{16,17}$ tabi tutulan grubu oluşturmaktadır. Örneklerin yüzey sertliklerini değerlendirmek için Vickers sertlik test cihazı (MMT-X; Matsuzawa Seiki Co. Ltd., Tokyo, Japan) kullanılmışır. Vicker's sertlik değeri, 50 g'ık yükün 30 saniye $^{18}$ boyunca örneğe uygulanmasıyla meydana gelen izin köşegenlerinin bilgisayar programı yardımıyla ölçülmesiyle elde edildi. Her bir örnek için merkezden perifere doğru yapılan üç ölçümün ortalaması alınarak ortalama yüzey sertlik değeri elde edilmiştir.

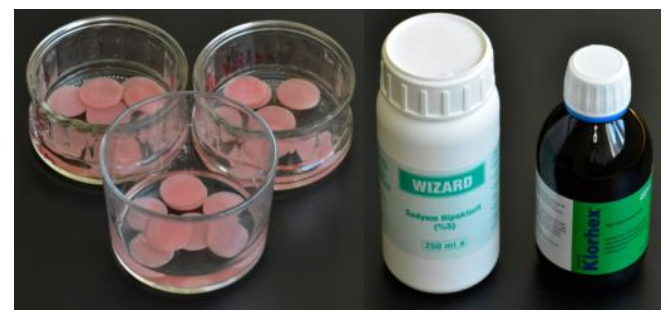

Şekil 2. Test örneklerinin $37^{\circ} \mathrm{C}$ de distile su, $\% 2^{\prime}$ lik glutaraldehit ve $\% 5^{\prime}$ lik sodyum hipoklorit içerisinde bekletilmesi.

İstatistiksel analizler IBM SPSS Statistics 20.0 bilgisayar programı kullanılarak yapılmıştır (IBM Corp. Released 2011. IBM SPSS Statistics for Windows, Version 20.0. Armonk, NY: IBM Corp., ABD). Verilerin normal dağılıma uygunluğunun ve varyansların homojenliğinin kontrolü Kolmogorov-Smirnov ve Levene testi ile yapılmıştır. Verilerinin normal dağılıma uygunluğu kontrol edildikten sonra yüzey sertliği ölçümleri 2 yönlü ANOVA ve Tukey's Honestly Significant Difference testi ile analiz edilmiştir. Tüm analizlerde istatistik anlamlıık düzeyi 0.05 olarak kabul edilmiştir.

\section{BULGULAR}

Tüm grupların yüzey sertliği sonuçlarının ortalamaları ve standart sapmaları Tablo $2^{\prime}$ de verilmiştir. Tüm gruplarda en yüksek yüzey sertlik değerleri kontrol gruplarında bulunmuştur. İki yönlü ANOVA'ya göre akrilik materyalleri, dezenfeksiyon 
yöntemi ve onların etkileşimleri arasında istatistiksel olarak anlamlı farklılık bulunmaktadır ( $p<0,001$, Tablo 3). Farklı dezenfeksiyon yöntemlerinin materyaller üzerine etkisi açısından, tüm uygulamalarda CAD/CAM akrilik gruplarında yüksek sertlik değerleri elde edilmiştir $(p<0,001)$. Isı ile ve kimyasal polimerize olan akrilik rezinler arasında \%5'lik Sodyum Hipoklorit solüsyonunda bekletme hariç istatistiksel olarak fark bulunmamaktadır ( $p>0,05)$. \%5'lik Sodyum Hipoklorit solüsyonunda bekletme sonucunda bu iki grubunda yüzey sertliklerinde istatistiksel olarak anlamlı azalma görülmüştür $(p<0,001)$.

Tablo 2. Dezenfektan solüsyon ve akrilik materyaller için ortalama sertlik değerleri

\begin{tabular}{|c|c|c|c|c|}
\hline & $\begin{array}{c}\text { Kontrol grubu } \\
\text { (Distile su) }\end{array}$ & $\begin{array}{c}\text { \% 2'lik } \\
\text { glutaraldehit }\end{array}$ & $\begin{array}{c}\text { \%1'lik Sodyum } \\
\text { Hipoklorit }\end{array}$ & $\begin{array}{c}\text { Mikrodalga } \\
\text { dezenfeksiyonu }\end{array}$ \\
\hline $\begin{array}{c}\text { Cad/Cam } \\
\text { Akrilik }\end{array}$ & $22,47( \pm 0,16)^{\mathrm{aA}}$ & $22,36( \pm 0,29)^{\mathrm{aA}}$ & $22,20( \pm 0,21)^{\mathrm{aA}}$ & $22,46( \pm 0,26)^{\mathrm{aA}}$ \\
\hline $\begin{array}{c}\text { Is ile } \\
\text { polimerize } \\
\text { olan akrilik }\end{array}$ & $17,70( \pm 0,20)^{\mathrm{bA}}$ & $17,52( \pm 0,23)^{\mathrm{bA}}$ & $15,85( \pm 0,17)^{\mathrm{bB}}$ & $17,67( \pm 0,11)^{\mathrm{bA}}$ \\
\hline $\begin{array}{c}\text { Kimyasal } \\
\text { polimerize } \\
\text { olan akrilik }\end{array}$ & $17,65( \pm 0,1)^{\mathrm{bA}}$ & $17,53( \pm 0,09)^{\mathrm{bA}}$ & $14,98( \pm 0,08)^{\mathrm{CB}}$ & $17,57( \pm 0,12)^{\mathrm{bA}}$ \\
\hline
\end{tabular}

Not: Dikey sütun içerisindeki farklı küçük harf ve yatay satır içerisindeki farklı büyük harf ile gösterilen değerler arasında istatistiksel olarak anlamlı farklılık vardır $(p<0,05)$.

Tablo 3. İki yönlü varyans analizi sonuçları

\begin{tabular}{|l|c|c|c|c|c|}
\hline Kaynak & SS & df & MS & F & P. \\
\hline Akrilik rezin & 755,770 & 2 & 377,885 & 10877,203 & $<, 001$ \\
\hline $\begin{array}{l}\text { Dezenfektan } \\
\text { Solüsyon }\end{array}$ & 53,466 & 3 & 17,822 & 512,994 & $<, 001$ \\
\hline $\begin{array}{l}\text { Akrilik rezin * } \\
\text { Dezenfektan } \\
\text { Solüsyon }\end{array}$ & 21,912 & 6 & 3,652 & 105,119 & $<, 001$ \\
\hline Error & 3,752 & 108 &, 035 & & \\
\hline Toplam & 43403,130 & 120 & & & \\
\hline
\end{tabular}

\section{TARTIŞMA}

Bu çalışmada farklı dezenfektan solüsyonların ve mikrodalga ile dezenfeksiyonun geleneksel muflalama yöntemiyle üretilen ısı ile ve kimyasal polimerize olan akrilik rezinlerin ve son yıllarda piyasaya çıkan prefabrike olarak polimerize edilmiş CAD/CAM akrilik blokların sertliğine olan etkisi değerlendirilmiştir. Çalışmadan elde edilen bulgulara göre; prefabrike olarak polimerize edilmiş CAD/CAM akrilik blokların sertlik değerleri, dezenfektan solüsyonlardan ve mikrodalga ile dezenfeksiyondan etkilenmemektedir ve geleneksel yöntemle elde edilen akrilik rezinlere göre daha yük- sektir. Isı ile ve kimyasal polimerize olan akrilik rezinlerin sertlik değerleri ise, \% 5'lik sodyum hipoklorit solüsyonundan istatistiksel olarak anlamlı derecede etkilenerek azalmıştır.

Protez kaide materyalleri ağız içerisinde pek çok etkiye maruz kalmaktadır. Bu etkilere başarılı bir şekilde karşı koyabilmeleri için yüksek yüzey sertlik değerlerine sahip olmaları gerekmektedir. Kalıcı yüzey değişikliğine karşı direnç olarak tanımlanan sertlik, materyalin yüzey bitirme işlemlerinin kolaylaştırılması ve yüzeyin çiziklere karşı direnci ile ilişkilidir ve materyalin yoğunluğunun bir göstergesidir. ${ }^{19-22} \mathrm{Bu}$ çalışmadaki protez kaide materyalleri dezenfeksiyon yöntemlerinden bağımsız karşılaştırıldıklarında, prefabrike olarak polimerize edilmiş CAD/CAM akrilik blokların diğer iki materyale göre daha yüksek sertlik değerlerine sahip olduğu görülmektedir. Bunun nedeninin yüksek sıcaklık ve basınç altında endüstriyel yöntemlerle polimerize edilen hazır akrilik blok üreticilerinin iddia ettiği gibi, bu blokların geleneksel materyallere oranla daha az artık monomer içermesi sonucu mekanik özelliklerinin gelişmiş olmasından kaynaklandığı düşünülmektedir. Bu sonuç, geleneksel olarak kullanılan ısı ile polimerize olan akrilik rezin ve yeni piyasaya çıkan prefabrike olarak polimerize edilmiş CAD/CAM akrilik bloğun mekanik özelliklerini karşılaştıran Ayman'ın ${ }^{12}$ çalışmasıyla paralellik göstermektedir. Gelecek çalışmalarda prefabrike olarak polimerize edilmiş CAD/CAM akrilik bloğun diğer mekanik özelliklerinin de araştırıması klinisyenlere yol gösteri olacaktır.

$\mathrm{Bu}$ çalışmanın ilginç sonuçlarından biri, kimyasal polimerize olmasına rağmen üretici firma tarafından tam ve parsiyel protez kaide materyali olarak kullanılması tavsiye edilen ve hakkında pek az araştırma bulunan kimyasal polimerize olan materyalin, \% $5^{\prime}$ lik sodyum hipoklorit solüsyonunda bekletilmesi hariç, sertlik değerlerinin geleneksel ISı ile polimerize olan akrilik rezinlerin sertlik değerleri arasında istatistiksel olarak anlamlı bir fark bulunmamasıdır. Bu çalışmaya göre, protez kaide materyali olarak kullanılabilen diğer materyallere göre daha basit laboratuvar işlemlerine sahip kimyasal polimerize olan materyalinin yeterli sertliğe sahip olduğu söylenebilmektedir.

$\mathrm{Bu}$ çalışmanın bulgularına göre; protez kaide materyallerini \% 2'lik glutaraldehit solüsyonunda bekletmek veya mikrodalga ile dezenfekte etmek, kontrol grubu ile karşılaştırıldığında, protez kaide materyallerin sertlik değerinde herhangi bir değişikliğe neden

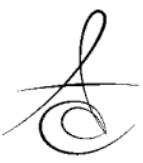


olmamıştır. Bu sonuç, geçmiş çalışmaların sonuçları ile paralellik göstermektedir. ${ }^{21,22} \% 5^{\prime}$ lik sodyum hipoklorit solüsyonunda bekletmek ise prefabrike olarak polimerize edilmiş CAD/CAM akrilik rezinlerin sertlik değerinde herhangi bir değişikliği neden olmaz iken, hem ISı ile hem de kimyasal polimerize olan akriliklerin sertlik değerinde istatistiksel olarak anlamlı düşüşe neden olmuştur. Konu ile alakalı yapılmış geçmiş çalışmaların sonuçları arasında çelişkiler bulunmaktadır. ${ }^{18,23}$ Bunun nedeni, önceki çalışmalarda kullanılan sodyum hipoklorit solüsyonun yüzdelerinin ve bekletme sürelerinin birbirinden farklı olması ile açıklanabilir. Bizim çalışmamızda \%5 'lik sodyum hipoklorit çözeltisinin kullanılmasının nedeni temin edilebilirliğinin kolay olmasından dolayıdır. Yüksek konsantrasyona sahip olan bu çözelti uygulandığı materyallerin içine penetre olarak materyalleri yumuşatmış olabilir. Gelecek çalışmalarda daha düşük konsantrasyonlu sodyum hipoklorit çözeltileriyle benzer materyallerin sertlik değerlerinin araştırılması gerekmektedir.

Çalışmamızda laboratuvarda bitirilmiş protezlerin hastaya tesliminden önceki dezenfeksiyon yöntemleri taklit edilmeye çalışılmıştır. Örnekler dezenfektan solüsyonlarda 1'er saat bekletilmişler ve 3 dakika süre ile mikrodalga dezenfeksiyonuna tabi tutulmuşlardır. Uzun dönemde bu uygulamaların materyallerde nasıl bir etki yaptığı araştırılmamıştır, ileriki çalışmalarda bu konunun da irdelenmesi gerekmektedir.

\section{SONUÇLAR}

Çalışmanın sınırları dahilinde,

1. Dezenfektan solüsyonda bekletme ve mikrodalga ile dezenfeksiyon sonrası prefabrike olarak polimerize edilmiş CAD/CAM akrilik rezin materyallerde yüzey sertliği değişimi gözlenmemiştir.

2. \%5'lik Sodyum Hipoklorit solüsyonunda bekletme ISI ile ve kimyasal polimerize olan akrilik rezinlerin yüzey sertliğinde azalmaya neden olmuştur.

3. Dezenfeksiyon yöntemlerinden bağımsız olarak prefabrike olarak polimerize edilmiş CAD/CAM akrilik rezinlerin yüzey sertliği test edilen diğer iki materyale göre daha yüksektir.

\section{S. Çağatay Dayan: ORCID ID: 0000-0003-3081-9618}

\section{KAYNAKLAR}

1. ADA Council on Scientific Affairs and ADA Council on Dental Practice: Infection control recommendations for the dental office and the dental laboratory. J Am Dent Assoc 1996;127:672-80.

2. Vafaee $F$, Radan $P$, Firouz $F$, et al: Microbial contamination of pumice powder and slurry in dental laboratories of Hamadan. Avi J Dent Res 2013;5:e19377.

3. Savabi O, Attar K, Nejatidanesh F, Goroohi H, Badrian $\mathrm{H}$. Effect of different chemical disinfectants on the flexural strength of heat-polymerized acrylic resins. Eur J Prosthodont Restor Dent 2013;21:105-8.

4. Vasconcelos LR, Consani RLX, Mesquita MF, Sinhoreti MAC. Effect of chemical and microwave disinfection on the surface microhardness of acrylic resin denture teeth. J Prosthodont 2013;22:298303.

5. Pawashe KG, Tewary S, Sanyal PK, Nilesh K. An In vitro Comparative Evaluation of Disinfectants on Standard and Clinical Microbial Strains on Heat Cure Resins. J Clin Diagn Res 2017;11:ZC54-ZC58

6. Muscat $Y$, Farrugia C, Camilleri L, Arias-Moliz MT, Valdramidis $\mathrm{V}$, Camilleri J. Investigation of acrylic resin disinfection using chemicals and ultrasound. J Prosthodont 2018;27:461-468.

7. Harrison $Z$, Johnson A, Douglas WI. An in vitro study into the effect of a limited range of denture cleaners on surface roughness and removal of Candida albicans from conventional heat-cured acrylic resin denture base material. J Oral Rehabil 2004;31:460-67.

8. Iseri $U$, Uludamar A, Ozkan YA. Effectiveness of different cleaning agents on the adherence of Candida albicans to acrylic denture base resin. Gerodontology 2011;28:271-76.

9. Silva $M M$, Vergani $C E$, Giampaolo $E T$, Neppelenbroek KH, Spolidorio DM, Machado AL, et al. Effectiveness of microwave irradiation on the disinfection of complete dentures. Int J Prosthodont 2006;19:288-93.

10. Gandhi N, Daniel S, Benjamin S, Kurian N, Varghese VS. Evaluation of surface microhardness following chemical and microwave disinfection of commercially available acrylic resin denture teeth. J Clin Diagn Res 2017;1:ZC87-ZC91

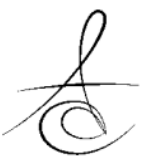


11. Çetindağ MT, Meşe A. Diş hekimliğinde kullanılan CAD/CAM (Bilgisayar Destekli Tasarım/Bilgisayar Destekli Üretim) sistemleri ve materyaller. J Dent Fac Atatürk Uni 2016;26:524-33.

12. Ayman AD. The residual monomer content and mechanical properties of CAD \CAM resins used in the fabrication of complete dentures as compared to heat cured resins. Electronic physician 2017;9:4766.

13. Srinivasan $M$, Gjengedal $H$, Cattani-Lorente $M$, Moussa $M$, Durual $S$, Schimmel $M$, Müller $F$. CAD/CAM milled complete removable dental prostheses: $A n$ in vitro evaluation of biocompatibility, mechanical properties, and surface roughness. Dent Mater J 2018;37:526-533.

14. Al-Dwairi ZN, Tahboub KY, Baba NZ, Goodacre CJ. A Comparison of the Flexural and Impact Strengths and Flexural Modulus of CAD/CAM and Conventional Heat-Cured Polymethyl Methacrylate (PMMA). J Prosthodont 2018 Jun 13. doi: 10.1111/jopr.12926.

15. Anusavice KJ, Phillips RW. Phillip's science of dental materials. 11th ed. St Louis; Elsevier: 2003. p. 33-47.

16. Orsi IA, Junior AG, Villabona CA, Fernandes FH, Ito IY. Evaluation of the efficacy of chemical disinfectants for disinfection of heat-polymerised acrylic resin. Gerodontology 2011;28:253-7.

17. Consani RL, Mesquita MF, de Arruda Nobilo MA, Henriques GE. Influence of simulated microwave disinfection on complete denture base adaptation using different flask closure methods. J Prosthet Dent 2007;97:173-8.

18. Neppelenbroek KH, Pavarina AC, Vergani CE, Giampaolo ET. Hardness of heat-polymerized acrylic resins after disinfection and long-term water immersion. J Prosthet Dent 2005;93:171-6.

19. Hamanaka I, Iwamoto M, Lassila LV, Vallittu PK, Takahashi $Y$. Wear resistance of injection-molded thermoplastic denture base resins. Acta Biomater Odontol Scand 2016;2:31-37

20. Suwannaroop P, Chaijareenont P, Koottathape N, et al. In vitro wear resistance, hardness and elastic modulus of artificial denture teeth. Dent Mater J 2011;30:461-468.
21. Jaiswal P, Pande N, Banerjee R, Radke U. Effect of repeated microwave disinfection on the surface hardness of a heat-cured denture base resin: An In vitro study. Contemp Clin Dent 2018;9:446-451.

22. Mahmood MA, Khalaf BS, Abass SM. Efficiency of Different Denture Disinfection Methods. Global J Bio-sci Biotech 2017;6:439-4.

23. Azevedo A, Machado AL, Vergani CE, Giampaolo ET, Pavarina AC, Magnani R. Effect of disinfectants on the hardness and roughness of reline acrylic resins. J Prosthodont 2006;15:235-42.

\section{Yazışma Adresi}

Süleyman Çağatay Dayan, DDS, PhD

Program of Dental Technicians, Istanbul

University Cerrahpasa, Istanbul, Turkey

https://orcid.org/0000-0003-3081-9618

Capa / Istanbul Turkey

Phone (business) : + 90212414 2020/30315

Phone (GSM): + 905335748701

Fax: + 902125253585

e-mail: suleyman.dayan@istanbul.edu.tr 